\title{
Determinants of Fertility Trend at District, Divisional and Regional Levels and Policy Implication for Poverty Alleviation
}

\author{
Md. Mizanur Rahman Sarker, ${ }^{1,}$, Nazneen Islam Nishat ${ }^{2}$, Mosammod Mahamuda Parvin ${ }^{3}$, \\ Anika Nawar Fagun ${ }^{4}$ \\ ${ }^{1}$ Department of Agricultural Statistics, Faculty of Agribusiness Management, Sher-e-Bangla Agricultural University, Dhaka, Bangladesh \\ ${ }^{2}$ Department of Agricultural Economics, Bangladesh Agricultural University, Mymensingh, Bangladesh \\ ${ }^{3}$ Department of Management and Finance, Sher-e-Bangla Agricultural University, Dhaka, Bangladesh \\ ${ }^{4}$ Department of Agribusiness and Marketing, Sher-e-Bangla Agricultural University, Dhaka, Bangladesh
}

Email address:

mrs_bd@yahoo.com (Md. M. R. Sarker)

${ }^{*}$ Corresponding author

\section{To cite this article:}

Md. Mizanur Rahman Sarker, Nazneen Islam Nishat, Mosammod Mahamuda Parvin, Anika Nawar Fagun. Determinants of Fertility Trend at District, Divisional and Regional Levels and Policy Implication for Poverty Alleviation. International Journal of Health Economics and Policy. Vol. 6, No. 3, 2021, pp. 92-99. doi: 10.11648/j.hep.20210603.13

Received: March 28, 2021; Accepted: April 13, 2021; Published: October 12, 2021

\begin{abstract}
Bangladesh is one of the most densely populated countries of the world (1278 persons per sq. km.) but it represents one of the few countries in developing world where the pace of fertility decline has been unparalleled over the last few decades despite pervasive poverty and under-development. It has been passing through a critical phase of fertility transition. The data was collected for this research from the following five sources: i. Bangladesh Multiple Indicator Cluster Survey (MICS) 2012-13 for fertility rate, contraceptive use, proportion of children engaged in work and access to mass media and ICT of women. ii. Statistical Yearbook of Bangladesh for literacy rate, iii. Population Census 2011 for population density characteristics of different districts, iv. Directorate of Agricultural Extension personnel for daily average wage rate of agricultural labor and v. Bangladesh Poverty Map, 2014 for the level of poverty of different districts. This study contributes to basic knowledge of the structural determinants of fertility rate in the Bangladesh by analyzing the expanded set of determinants at district level, namely contraceptive use, literacy rate, daily wage rate of agricultural labor, population density, child labor, access to mass media and ICT of women and poverty level using spatial data analysis techniques. In this study, the binary join matrix/binary contiguity matrix and inverse distance spatial weight matrix techniques are used to capture spatial dependence in the data. This analysis extends the spatial model by allowing spatial dependence to vary across divisions and regions. The results strongly indicate that the fertility associated with contraceptive use, literacy rate, daily wage rate of agricultural labor, child labor, poverty level and their neighbors' districts. These results suggest that district should pay particular attention to policies in neighboring districts and policy maker should realize that declining the fertility rate in neighboring districts are likely to affect fertility rate in their own district, therefore, a key issue for policy development is how to stimulate the contraceptive use, educational attainment, promote daily wage of agricultural labor and decrease child labor and poverty level could control the fertility and result in sustainable development and poverty alleviation of regions that are both high fertility and economically lagging. This needs to be addressed both in terms of national level policies and more emphatically within regional and sub-regional development strategies than it has been hither.
\end{abstract}

Keywords: Spatial Modeling, Fertility Rate, Poverty, Bangladesh 


\section{Introduction}

Bangladesh is one of the most densely populated countries of the world ( 1278 persons per sq. $\mathrm{km}$.) but it represents one of the few countries in developing world where the pace of fertility decline has been unparalleled over the last few decades despite pervasive poverty and under-development. It has been passing through a critical phase of fertility transition. In the early 1970 s the total fertility rate was about seven children and women in the first demographic and Health Survey 1994 and 2.08 children per woman in 2017. Fertility is the most important determinant of population change. Bangladesh has achieved remarkable success in reducing fertility rate during last three decades. For this reason, compared to migration and mortality, fertility has received huge attention among policy makers. Fertility is not only responsible for population growth but also the main factor determining the change in age composition of a population $[18,23]$. Although inherently a biological process, human fertility is strongly influenced by societal and cultural factors that make it a collective as well as individual matter. A society's continuation depends on its fertility, and for this reason all societies possess elements of culture that promote and encourage some level of reproduction. The 2014 Bangladesh Demographic and Health Survey data shows that the total fertility rate (TFR) in Bangladesh has become stagnant since 2011. In addition, the rate of progress is not uniform all over the country though Bangladesh government has initiated several programs to ensure equity in access to health and family planning. On the other hand, Bangladesh is expected to add around 17 million more population, due to the effects of population momentum in spite of having low birth and low death rates as well as achieving replacement level fertility [17]. Under these circumstances, it is important to identify the trends and determinants of fertility differentials in Bangladesh. Among cultural characteristics, in this study we have looked at the impact of religion and access to media on fertility in Bangladesh. Consistent with the expectation, it was found that Muslims had higher TFR than non-Muslims (2.6 and 2.4 respectively). Regarding access to media, we noticed that those who did not have exposure to media had higher TFR (2.8) than those who have exposure to media (2.4) [8].

Although there has been significant reduction in fertility levels at the national level, regional variations continue to persist. Different regions showed different degree of achievements in reducing the level of fertility. The study focuses on detecting spatial dependence, and investigating the determinants of fertility which contributed major role in fertility decline. There are substantial differences in ruralurban fertility across the globe [19]. Bangladesh is not an exception in this case. Consistent with previous research, it was found that TFR in rural areas was higher as compared to urban areas (2.6 and 2.3 respectively). Similarly, among women living in rural areas 41.9 percent had more than two children which is 33.2 percent among women living in urban areas. However, the differences in fertility between rural and urban areas are diminishing over time in Bangladesh. However, there are substantial variations in fertility by division in Bangladesh. In 2014, four divisions have total fertility rate above the replacement level. These divisions are Sylhet (2.9), Chittagong (2.5), Dhaka (2.3) and Barisal (2.2) on the contrary, three divisions have fertility levels either at replacement level or below the replacement level: Rajshahi (2.1), Khulna (1.9), and Rangpur (1.9). The divisional variations in fertility by place of residence (rural-urban) or division have been partly attributed to their differences in socioeconomic conditions and differences in religiosity [15]. This paper is important for several reasons. First, the present study is the first to address the spatial dimension for fertility in Bangladesh; second, this methodology provides consistent and efficient estimation; and third, the results have important implications for policies at both regional and national levels, especially those involving regional coordination for achieving replacement level fertility.

\section{Methodology}

\subsection{Data Sources}

The data was collected for this research from the following five sources:

i. Bangladesh Multiple Indicator Cluster Survey (MICS) 2012-13 (BBS \& UNICEF, 2014) for fertility rate, contraceptive use, proportion of children engaged in work and access to mass media and ICT of women [9].

ii. Statistical Yearbook of Bangladesh for literacy rate [5].

iii. Population Census 2011 for population density characteristics of different districts [6].

iv. Directorate of Agricultural Extension personnel for daily average wage rate of agricultural labor and

v. Bangladesh Poverty Map, 2014 for the level of poverty of different districts [7].

\subsection{District Level Spatial Models}

A spatial lag model is a formal representation of the outcome of processes of social and spatial interaction. Spatial lag or regressive spatial autoregressive model includes a spatial lagged dependent variable on the right hand side of the regression specification (Anselin, 1988). A second approach to spatial autoregressive process or spatial autoregressive modeling is known as the spatial error model. Examining the spatial effects on district level fertility rate of Bangladesh. We used the basic model of spatial correlation developed by Anselin (1988), Cliff \&Ord (1981) and Coughlin \& Garrett (2004) allows for spatial dependence in the dependent variable or in the error component $[3,11,12]$,

$$
\begin{gathered}
y=\rho W y+X \beta+\varepsilon \\
\varepsilon=\lambda W \varepsilon+u
\end{gathered}
$$

Where $X$ is an $(n x(k+1))$ matrix of observations on the explanatory variables, $\mathrm{y}$ and $\varepsilon$ are $\mathrm{n} \times 1$ vectors and $\beta$ is a $(\mathrm{k}+1)$ vector. If $\mathrm{E}(\varepsilon \varepsilon)=\sigma^{2} \mathrm{I}$, where $\mathrm{I}$ is the nxn identity matrix 
then the arrangement properties of the attributes are irrelevant to the specification of the model. $W y$ and $W \varepsilon$ are exogenously specified nxn weights matrices, lag and error, respectively. The scalar $\rho$ and $\lambda$ are spatial lag and spatial error coefficients, respectively. The equation 2 is necessary for estimating the spatial error coefficient lamda $(\lambda)$.

The following district model was used for detecting the spatial effect:

$$
\begin{aligned}
& y=\rho W y+\beta_{0}+\beta_{1} c u+\beta_{2} c l+\beta_{3} \text { ammict }+\beta_{4} l r \\
& +\beta_{5} p d+\beta_{6} d w r+\beta_{7} p l+\varepsilon, \text { where }, \varepsilon=\lambda W \varepsilon+\mu
\end{aligned}
$$

where $\mathrm{y}$ is the fertility rate of a district of Bangladesh, cuis the contraceptive use, $c l$ is the percentage of child labor, ammict is the access to mass media and ICT of women, $l r$ is literacy rate, $p d$ is the population density in per square kilometer, $d w r$ is daily wage rate of agricultural labor and, $p l$ is the poverty level of a district. To compare the models, I consider the Akaike's Information Criterion (AIC) and the Bayesian Information Criterion (BIC) based on the ML method $[2,21]$. The binary join/contiguity matrix and the inverse distance spatial weights matrix specifications of $\mathrm{W}$ are used in the empirical models to highlight any differences in spatial patterns of fertility rate. The various measures of spatial distance that have been discussed in the literature [10, 12-14, 16]. I follow Hern'andez-Murillo (2003), Coughlin \& Garrett (2004) and Sarker (2012) and consider the distance between district population centers $[16,12,20]$.

\subsection{Relation Between Spatial Lag ( $\rho)$ and Spatial Error ( $\lambda$ ) Coefficients}

The scalar $\rho$ is the spatial lag coefficient, positive spatial correlation exists if $\rho>0$, negative spatial correlation if $\rho<0$, and no spatial correlation if $\rho=0$ and $\lambda$ is the spatial error coefficient. The errors are positively correlated if $\lambda>0$, negatively correlated if $\lambda<0$, and spatially uncorrelated if $\lambda=0$. The cases under the consideration of the models (1) and (2) are following:

Case (i): $\rho=0, \lambda=0$

Under this assumption, spatial lag weight matrix component and spatial error weight matrix component will be zero and estimating the parameter $\beta$, and then the general spatial model (1) and (2) reduce to the standard regression model. There is no spatial or serial error correlation in this model.

Case (ii): $\rho \neq 0, \lambda=0$

The second case focuses on the spatial lag and ignoring the presence of spatial error correlation. If setting $\lambda=0$ and estimating $(\rho, \beta)$, it is spatial lag model which is clearly more meaningful. The general spatial model equation (1) and (2) tends to spatial error model (2). In such models, the dependent variable in location $\mathrm{i}$ is not only determined by covariates $(\mathrm{X})$ specific to location $\mathrm{i}$, but also by the value of the same dependent variable at other locations. Anselin and Bera (1998) suggest two interpretations of the spatial lag model [4]. Either, it suggests true contagion (spatial spillovers, copy-catting or diffusion). This requires, however, that the observed spatial units match the true economic units and that the spillover is modeled theoretically. Or, the alternative interpretation results from situations where there is a mismatch between the true spatial scale and the observed one, e.g., census vs. economic units.

Case (iii): $\rho=0, \lambda \neq 0$

The third case focuses on the error term and ignoring the presence of spatial lag correlation. If $\rho=0$ and estimating the other parameters $\lambda$ and $\beta$, then the general spatial model (1) and (2) take the equation (1) form. This case in the error term may arise through omitted variables that have a spatial dimension, such as climate, industrial patterns, or exogenous shocks [1]. Spatial error dependence is likely to be a problem in social science applications using cross sectional data due to the poor choice of spatial units, but also due to the predominance of spatial interaction and spatial externalities. In practice, this aspect of regression modeling is typically ignored, since the focus of attention in cross-sectional data tends to be on heteroskedasticity (i.e., unequal error variance) However, given that the consequences of ignored spatial error dependence are at least as serious as those of ignored heteroskedasticity, it should be standard practice to test regression residuals in cross-sectional studies.

Case (iv): $\rho \neq 0, \lambda \neq 0$

The fourth case considers the both spatial lag and spatial error term. In spatial lag + error models all three parameters ( $\rho, \lambda$ and $\beta$ ) are estimated. These models may be viewed in practice as resulting from poorly specified lag matrices Wy which results in spatial interactions in the error terms that need to be taken into account WE [4]. The most general spatial lag model and error model under the case four takes the following form;

$$
y=p W y+X \beta+\lambda W \varepsilon+\mu
$$

\subsection{Divisional and Regional Model}

The spatial model with regional/divisional spatial correlation coefficients may be written as:

$$
y=\sum_{k=1}^{D} \rho_{k} W_{k} y+X \beta+\varepsilon
$$

where,

$$
\varepsilon=\sum_{k=1}^{D} \lambda_{k} W_{k} \varepsilon+u=\left(\mathrm{I}-\sum_{k=1}^{D} \lambda_{k} W_{k} \varepsilon\right)^{-1} u
$$

Here, $\mathrm{D}$ denotes the total number of divisions and regions and $\rho_{\mathrm{k}}$ and $\lambda_{\mathrm{k}}$ denote the spatial lag and spatial error lag coefficients, respectively, for division $k$. Each coefficient, $\rho_{\mathrm{k}}$, measures the average correlation between a district in region $\mathrm{k}$ and the spatially weighted household knowledge of all other districts. $\mathrm{W}_{\mathrm{k}}$ remains the $(\mathrm{N} \times \mathrm{N})$ spatial weights matrices $w_{k}$. Each matrix $\mathrm{W}_{k}$ is constructed by premultiplying by a dummy variable that equals unity if district $i$ is located in division/region $k$, and zero otherwise. In the 
case of a contiguity matrix, household knowledge in district $i$ located in region $k$ to be affected by household knowledge of all districts $j$ that border district $i$, regardless of whether district $j$ is in the same division and region as district $i$.

\subsection{Model Comparison}

To compare models, I consider the Akaike's Information Criterion (AIC) and the Bayesian Information Criterion (BIC) based on the ML method [2, 21]. AIC, a penalized $\log$ likelihood criterion is defined by

$$
\mathrm{AIC}=-2 \ell+2 K
$$

Where $\ell$ is the $\log$ likelihood and $\mathrm{k}$ is the number of parameters.

$$
\mathrm{SC}=-2 \ell+K \ln (n)
$$

\section{Results and Discussions}

\subsection{Fertility Rate of Women}

Bangladesh has achieved remarkable success in reducing

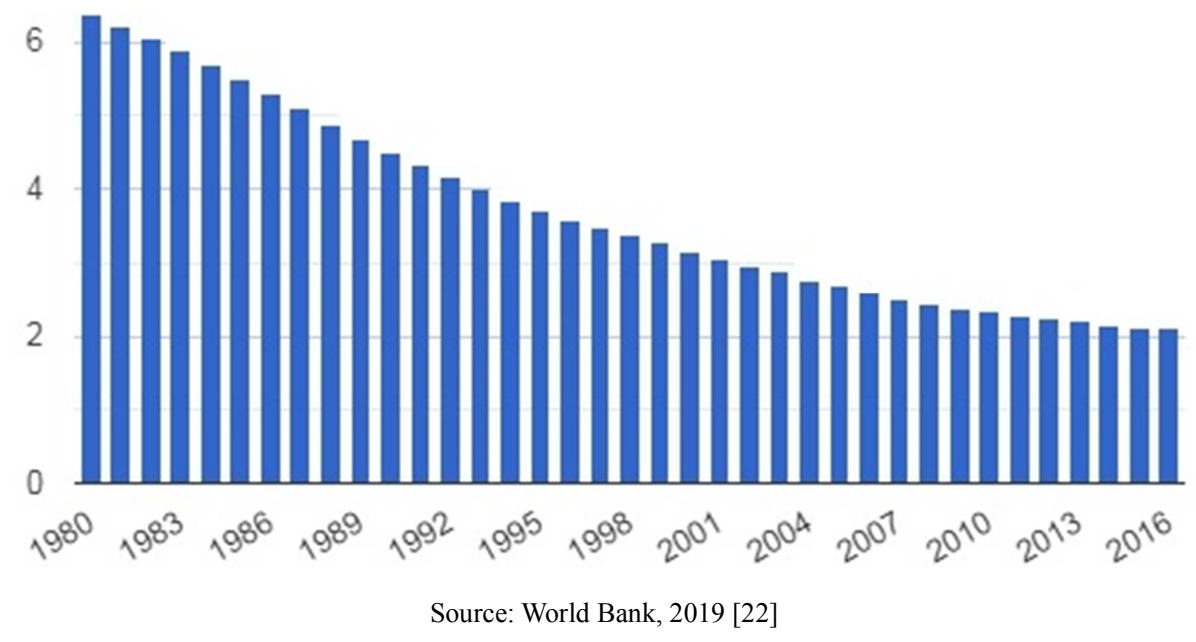

Figure 1. Fertility rate of women during 1980 to 2016.

\subsection{Coefficients of Determinates of Fertility Rate with Spatial Estimates of Binary Join and Inverse Distance Weights}

The findings are presented in table 1 suggest that spatial dependence in district by using binary join weight may be the best model for spatial lag. The findings from table 2 suggest that the spatial lag model is the best model for expressing the spatial dependence of district fertility rate by using inverse distance weight. This is supported by the AIC and SC, which are directly comparable across models and weigh the explanatory power of a model (based on the maximized value of the log-likelihood function). Table 1 presents the spatial estimation results. Column 1 in table 1 corresponds to a standard regression model where no spatial effects among the neighboring districts are taken into account. The coefficients represent the effects of the explanatory variables on fertility rate about arsenic pollution. Column 2 corresponds to a total fertility rate (TFR) from 6.3 children per woman in 1975 to 2.1 children in 2016. Earlier research attributed this success in declining fertility to a large extent to the successful implementation of family planning programs in Bangladesh [18]. Figure 1 presents the fertility rates in Bangladesh during the period of 1980 to 2016 based. The minimum births per woman was 2.1 in 2016 and a maximum of 6.36 births per woman in 1980. It should be mentioned that 2.10 is an important marker of the fertility level which is considered as the replacement level fertility where population will stop increasing unless there is an effect of population momentum. In fact, population momentum indicates growth of population due to age structure rather than the rate of natural increase or total fertility. The age structure will affect growth if, for example, the proportion of women in the childbearing age range is increasing due to higher fertility rates in the past [17]. From the trend below it is cleared to understand, the fertility rate of Bangladesh is decreasing every year, where the decreasing rate was unparallel from 1980 to 2013 (3.36 to 2.2) and near to parallel 2014 to 2016 . 
literacy rate, access to mass media and daily wage rate of agricultural labor of a district. Child labor and poverty level have positive impact on the fertility rate of women for all model. In the models corresponding to the binary spatial weights, the spatial lag in the dependent variable is statistically significant at the 5 percent level and the spatial lag in the error term is not statistically significant. The results from a join spatial model (spatial lag +error) in column 4. The numerical interpretation of the estimated coefficients is as follows. The findings in column 2 of table 1 , for example, suggest that a $1 \%$ increase the literacy rate, on average, a decrease of about 0.11 percentage fertility rate of women. A decrease of child labor, 1 person per household induces decrease. 081 percentage fertility rate.

Table 1. Coefficients of determinates with spatial estimates by using the binary weights of the fertility.

\begin{tabular}{|c|c|c|c|c|}
\hline \multirow{2}{*}{ Variables } & \multicolumn{4}{|l|}{ Coefficients } \\
\hline & No Spatial Effect & Spatial Lag & Spatial Error & Spatial Lag \& Error \\
\hline Constant & $0.398 * *(0.195)$ & $0.479 * * *(0.139)$ & $0.439 * *(0.189)$ & $0.278 * * *(0.103)$ \\
\hline Contraceptive use & $-0.110 * *(0.052)$ & $-0.164 * *(0.081)$ & $-0.156 * *(0.073)$ & $-0.137 * * *(0.486)$ \\
\hline Child labour & $0.079 * * *(0.027)$ & $0.081 * *(0.041)$ & $0.057 * *(0.026)$ & $0.061 * *(0.030)$ \\
\hline Access to mass media (MM) and ICT of women & $-0.006(0.036)$ & $-0.002(0.030)$ & $-0.007(0.034)$ & $-0.009(0.022)$ \\
\hline Literacy rate $(\%)$ & $-0.089 * *(0.044)$ & $-0.113 * *(0.054)$ & $-0.095 * *(0.047)$ & $-0.101 * *(0.049)$ \\
\hline Population density (per sq. km) & $-0.0022(0.004)$ & $-0.001(0.003)$ & $-0.002(0.003)$ & $0.0004(0.003)$ \\
\hline Poverty level & $0.019 * *(0.095)$ & $0.021 * *(0.014)$ & $0.018 * *(0.008)$ & $0.019 * *(0.009)$ \\
\hline \multirow{2}{*}{ Rho Lamda } & -- & $0.366 * *(0.152)$ & -- & $0.417 * * *(0.164)$ \\
\hline & -- & -- & $0.363(0.478)$ & $-0.372(0.520)$ \\
\hline Log Likelihood & -246.81 & -243.622 & -246.524 & -245.326 \\
\hline AIC & 511.62 & 509.244 & 513.048 & 510.653 \\
\hline $\mathrm{BIC}$ & 532.05 & 532.241 & 534.639 & 532.992 \\
\hline
\end{tabular}

Standard error in the parentheses. Asterisks $* *$ and $* * *$ indicate statistical significance at the $5 \%$ and $1 \%$ levels, respectively.

The results from the models that both the spatial lag (column 2) and error (column 3) models reveal that the spatial lag is significantly different from zero but error coefficient is not significantly different from zero. However, the Akaike Information Criterion (AIC), Schwarz Criterion (SC) and the log-likelihood statistics all reveal that the spatial lag model presented in columns 2 is provided a better fit than the spatial error model. The results from the model that include both the spatial lag and error term (column 4) reveals that only the spatial lag coefficient is significantly different from zero. The findings are presented in table 1suggest that spatial dependence in district fertility rate may be the best model using a spatial lag. This is supported by the AIC and $\mathrm{SC}$, which are directly comparable across models and weigh the explanatory power of a model (based on the maximized value of the log-likelihood function).

Table 2. Coefficients of determinates with spatial estimates by using the inverse distance spatial weights of the fertility rate.

\begin{tabular}{|c|c|c|c|c|}
\hline \multirow{2}{*}{ Variables } & \multicolumn{4}{|l|}{ Coefficients } \\
\hline & No Spatial Effect & Spatial Lag & Spatial Error & Spatial Lag \& Error \\
\hline Constant & $0.398 * *(0.195)$ & $0.473 * * *(0.157)$ & $0.588 * * *(0.189)$ & $0.283 * * *(0.097)$ \\
\hline Contraceptive use & $-0.110 * *(0.052)$ & $-0.136 * *(0.67)$ & $-0.135 * *(0.059)$ & $-0.131 * *(0.061)$ \\
\hline Child labour & $0.079 * * *(0.027)$ & $0.073 * * *(0.036)$ & $0.078 * *(0.038)$ & $0.045 * *(0.022)$ \\
\hline Access to mass media (MM) and ICT of women & $-0.006(0.036)$ & $-0.008(0.030)$ & $-0.004(0.028)$ & $-0.005(0.094)$ \\
\hline Literacy rate $(\%)$ & $-0.089 * *(0.044)$ & $-0.104 * *(0.501)$ & $-0.086 * *(0.042)$ & $-0.070 * *(0.034)$ \\
\hline Population density (per sq. km) & $-0.0022(0.004)$ & $-0.003(0.002)$ & $-0.002(0.003)$ & $-0.003(0.003)$ \\
\hline Poverty level & $0.019 * *(0.084)$ & $0.017 * *(0.085)$ & $0.014 * *(0.069)$ & $0.013 * *(0.063)$ \\
\hline Rho & -- & $0.488 * * *(0.128)$ & -- & $0.501 * * *(0.123)$ \\
\hline Lamda & -- & & $-4.735 *(2.476)$ & $-3.147(2.209)$ \\
\hline Log Likelihood & -246.81 & -237.665 & -245.032 & -240.269 \\
\hline AIC & 511.62 & 497.330 & 510.064 & 500.539 \\
\hline $\mathrm{BIC}$ & 532.05 & 521.077 & 531.653 & 522.127 \\
\hline
\end{tabular}

An alternative definition of neighborhood effects in the fertility rate allows fertility rate in nearby districts that are not necessarily adjacent to affect a specific district. In this case, the use of inverse-distance spatial weights is more appropriate to identify spatial interactions among the distance spatial weights of districts. Columns 2 through 4 in table 2 present the estimation results using spatial weights computed as the inverse distance between districts' population centers. The results are qualitatively similar to those in table1. The results from a joint spatial model, in column 4, suggest spatial interaction in both the dependent variable and in the error term. The coefficients for the spatial lag in columns 2 and 4 are positive, supporting the conclusion that there is a positive interaction in the fertility rate among the districts. The spatial coefficients are statistically significant in model 2 and model 4 but the spatial error coefficients are statistically insignificant in model 3 and model 4. The AIC, BIC and log likelihood statistics suggest that the spatial models show 
better fit than non-spatial model (column1 of table 2). Among the four specifications, log likelihood value is lowest for join (spatial lag + error) model (column 4) and AIC and SC are lowest in spatial lag model (column 2). The findings from table 2 suggest that the spatial lag model is the best model for expressing the spatial dependence of fertility rate.

\subsection{Coefficients of Divisional and Regional Spatial Estimates of Fertility Rate}

Tables 3 and 4 present the results from four specifications that allow for regional and divisional differences in the spatial correlation coefficients by using binary joins and inverse distance contiguity. Tables 3 and 4 present the results from four specifications that allow for regional and divisional differences in the spatial correlation coefficients by using binary joins and inverse distance contiguity. Because our results in table 1 indicates that a spatial lag models are the appropriate specifications, therefore, we only consider for divisional and regional differences in spatial lag coefficients among the four specifications. Table 3 reports the estimates from the spatial lag model that allows for regional-specific spatial lag coefficients at the administrative division level, while Table 4 allows regional-specific spatial lag coefficients at the regional (North, South) level when neighbors are defined as common border. We find considerable evidence that the effects of spatial correlation in the dependent variable vary by division.

As reported in table 4 two regional correlation coefficients are positive and statistically significant at the 1percent level or 5 percent level; furthermore, visual inspection of the estimated coefficients suggests differences in the magnitude of spatial correlation between a district in a given region and all other districts. Estimates of positive spatial correlation in four divisions range from 0.219 to 0.317 when neighbors are defined by binary joins matrix and 0.301 to 0.458 when spatial weight are defined by inverse distance matrix.

Table 3. Coefficient of determinates of the fertility at divisional level.

\begin{tabular}{lll}
\hline \multirow{2}{*}{ Variables } & Coefficients & Distance \\
\cline { 2 - 3 } & Contiguity & $0.261^{* * *}(0.088)$ \\
\hline Constant & $0.623 * *(0.209)$ & $-0.108^{* *}(0.045)$ \\
Contraceptive use & $-0.102^{* *}(0.051)$ & $0.072^{* *}(0.035)$ \\
Child labour & $0.074^{* *}(0.032)$ & $-0.004(0.029)$ \\
Access to mass media (MM) and ICT of women & $-0.002(0.033)$ & $-0.063 * *(0.031)$ \\
Literacy rate (\%) & $-0.075 * *(0.037)$ & $-0.003(0.003)$ \\
Population density (per sq. km) & $-0.002(0.002)$ & $-0.006^{* * *}(0.0019)$ \\
Daily wage rate of agricultural labour (TK.) & $-0.006 * * *(0.002)$ & $0.010(0.142)$ \\
Poverty level & $0.019(0.151)$ & $0.458^{* * *}(0.158)$ \\
$\rho_{1}$ (Dhaka) & $0.317 * *(0.153)$ & $0.301 * *(0.124)$ \\
$\rho_{2}$ (Chittagong) & $0.227(0.160)$ & $0.388^{* * *}(0.130)$ \\
$\rho_{3}$ (Khulna) & $0.284 *(0.125)$ & $0.331 * *(0.143)$ \\
$\rho_{4}$ (Rajshahi) & $0.219(0.165)$ & -237.763 \\
Log Likelihood & -239.933 & 501.525 \\
AIC & 505.868 & 529.591 \\
BIC & 533.933 & \\
\hline
\end{tabular}

Table 4. Coefficients of determinates of the fertility of women at regional level.

\begin{tabular}{lll}
\hline \multirow{2}{*}{ Variables } & Coefficients & Distance \\
\cline { 2 - 3 } & Contiguity & $0.371 * *(0.188)$ \\
\hline Constant & $0.246^{* *}(0.135)$ & $-0.102 * *(0.043)$ \\
Contraceptive use & $-0.130^{* *}(0.051)$ & $0.054 * *(0.021)$ \\
Child labour & $0.077 * *(0.032)$ & $-0.002(0.026)$ \\
Access to mass media (MM) and ICT of women & $-0.009(0.032)$ & $-0.062 * *(0.028)$ \\
Literacy rate (\%) & $-0.050^{* *}(0.025)$ & $-0.003(0.0026)$ \\
Population density (per sq. km) & $-0.001(0.003)$ & $-0.007 * * *(0.0021)$ \\
Daily wage rate of agricultural labour (TK.) & $-0.007 * *(0.003)$ & $0.011(0.145)$ \\
Poverty level & $0.013(0.157)$ & $0.488^{* * *}(0.171)$ \\
$\rho_{1}$ (North) & $0.336 * *(0.138)$ & $0.489 * * *(0.169)$ \\
$\rho_{2}$ (South) & $0.356 * *(0.156)$ & -240.269 \\
Log Likelihood & -245.240 & 502.539 \\
AIC & 512.480 & 526.286 \\
BIC & 536.223 & \\
\hline
\end{tabular}

Standard error in the parentheses. Asterisks $* *$ and $* * *$ indicate statistical significance at the $5 \%$ and $1 \%$ levels, respectively.

Estimates of spatial correlation in two regions are 0.336 and 0.356 when neighbors are defined by binary joins matrix and 0.488 and 0.489 when spatial weight are defined by inverse distance matrix. All spatial coefficients for regional are positive and statistically significant $(\mathrm{P}<0.01$ or 0.05$)$. The
AIC, BIC and log likelihood statistics suggest that the inverse distance matrix contiguity spatial models show better fit than inverse distance spatial weights matrix models in both regional and divisional models. 


\subsection{Equality of Spatial Coefficients of Divisional and Regional Models of Fertility Rate}

The spatial coefficients in the Dhaka, Chittagong, Khulna and Rajshahi divisions as well as Northern and Southern regions of Bangladesh are substantially larger when neighbors are defined by common border as opposed to inverse distance. Using the inverse distance matrix neighbor definition, the results from the divisional and regional specific models in table 5 suggest that the spatial effects on fertility rate are more or less homogeneous across divisions and regions although the test results are shown that the spatial correlations for districts in each division are statistically not homogeneous in the Dhaka and Chittagong as well as Dhaka and Rajshahi divisions. The test results indicate that spatial correlations are not significantly different across all regions when neighbors are defined by the inverse distance. We present results the seven pair wise hypothesis tests of the equality of the spatial correlation coefficients when neighbors defined as common border from the fourteen possible pair wise equality tests at the divisional level and regional level. There are six pair wise equality tests at the divisional level and one pair wise equality test at the regional level.

Table 5. Spatial coefficients equality with binary join weights for divisions and regions of poverty distribution.

\begin{tabular}{|c|c|c|c|c|c|c|}
\hline & Dhaka & Chittagong & Khulna & Rajshahi & North & South \\
\hline Dhaka & ---- & $* *$ & ns & * & & \\
\hline Chittagong & ** & ---- & ns & ns & & \\
\hline Khulna & ns & ns & ---- & ns & & \\
\hline Rajshahi & $*$ & ns & $\mathrm{ns}$ & ---- & & \\
\hline North & & & & & ns & ns \\
\hline South & & & & & ns & ns \\
\hline
\end{tabular}

Asterisk* indicates statistical significance at the $10 \%$ and ns means statistical insignificance.

\section{Conclusions}

The results strongly indicate that the fertility associated with contraceptive use, literacy rate, daily wage rate of agricultural labor, child labor, poverty level and their neighbors' districts. This study is the first to directly model and provide estimates on the spatial interdependence of a district level fertility rate and the approach taken here affords the estimation of consistent and efficient coefficients. These results suggest that border district should pay particular concentration to policies in adjacent districts and policy architect should understand that declining the productiveness rate in neighboring districts are likely to affect fecundity rate in their own district, therefore, a key issue for policy expansion is how to motivate the contraceptive use, educational attainment, promote daily wage of agricultural labor and decrease child labor and poverty level could have power over the productiveness and result in sustainable development and poverty alleviation of regions that are both high fertility and economically lagging. This needs to be addressed both in terms of national level policies and more emphatically within regional and sub-regional development strategies.

\section{References}

[1] Abreu, M., de Groot, H. L. F., Florax, R. J. G. M. 2004. Spatial patterns of technology diffusion: An empirical analysis using TFP. Tinbergen Institute Discussion Paper (Paper No. TI 2004-079/3), Amsterdam.

[2] Akaike, H. (1974). A new look at the statistical model identification. IEEE Transactions on AutCont, 19, 716-723.

[3] Anselin, L. (1988). Spatial Econometrics Methods and Models. New York: Kluwer Academic.
[4] Anselin, L., Bera, A. 1998. Spatial Dependence in Linear Regression Models with an Introduction to Spatial Econometrics, In A. Ullah \& D. Giles (Eds.) Handbook of Applied Economic Statistics, New York.

[5] BBS. (2012). Statistical Yearbook of Bangladesh. Ministry of Planning, Government of the People's Republic of Bangladesh. Dhaka: Bangladesh Bureau of Statistics.

[6] BBS. (2013). Population Census 201, National Report (Provisional), Ministry of Planning, Government of the People's Republic of Bangladesh, Dhaka: Bangladesh Bureau of Statistics.

[7] BBS (2014). Bangladesh Poverty Map. Ministry of Planning, Government of the People's Republic of Bangladesh. Dhaka: Bangladesh Bureau of Statistics.

[8] BBS (2015). Population Monograph Of Bangladesh. Fertility Differentials In Bangladesh: Trends And Determinants. Ministry of Planning, Government of the People's Republic of Bangladesh. Dhaka: Bangladesh Bureau of Statistics.

[9] BBS-UNICEF. (2014). Multiple Indicators Clusters Survey Bangladesh 2012-13 (Key findings), Dhaka: Bangladesh Bureau of Statistics.

[10] Bodson, P., \&Peeters, D. (1975). Estimation of the Coefficients of a Linear Regression in the Presence of Spatial Autocorrelation: An Application to a Belgian Labor Demand Function. Environment and Planning A, 7, 455-472.

[11] Cliff, A., \& Ord, J. (1981). Spatial Processes: Models and Application. London: Pion Ltd.

[12] Coughlin, C., \& Garrett T. A. (2004). Spatial Probit and the Geographic Patterns of State Lotteries. Working Paper, 2003042B, Federal Reserve Bank of St. Louis.

[13] Dubin, R. A. (1988). Estimation of Regression Coefficients in the Presence of Spatially Autocorrelated Error Terms. Review of economics and statistics, 70, 466-474. 
[14] Garrett, T. A., \& Marsh, T. L. (2002). The Revenue Impacts of Cross-Border Lottery Shopping inthe Presence of Spatial Autocorrelation. Regional Science and Urban Economics, 32, 501-519.

[15] Islam, M. M., Rob, U., \& Chakraborty, N. (2003). Regional variations in fertility in Bangladesh. Genus, 59 (3/4): 103-145.

[16] Hern'andez-Murillo, R. (2003). Strategic Interaction in Tax Policies Among States. Federal Reserve Bank of St. Louis Review, 85 (3), 47-56.

[17] Jones, G. (eds.). (2015). The Impact of Demographic Transition on Socioeconomic Development in Bangladesh: Future Prospects and Implications for Public Policy. Dhaka, UNFPA.

[18] Khuda, B., \& Hossain, M. B. (1996). Fertility decline in Bangladesh: toward an understanding of major causes. Health Transition Review, Supplement 6 1996, 155-167.
[19] Reed, H., Rona B. and John C. (eds.). 1999. "The Role of Diffusion Processes in Fertility Change in Developing Countries: Report of a Workshop." Committee on Population, National Research Council. Washington, DC: National Academy Press.

[20] Sarker, M. M. R. (2012). Spatial modeling of households' knowledge about arsenic pollution in Bangladesh. Social Science \& Medicine 74, 1232-e1239.

[21] Schwartz, G. (1978). Estimating the dimension of a model. Annals of Statistics, 6, 461-464.

[22] World Bank. 2019. Bangladesh: Fertility rate. https://www.theglobaleconomy.com/Bangladesh/Fertilityrate/( accessed 19 April 2019).

[23] Rabbi, A. M. F., \& Kabir, M. (2015). Explaining fertility transition of a developing country: an analysis of quantum and tempo effect. Fertility Research and Practice 2015, 1:4. 